\title{
Analysis on the Policy and Technology Application of Japan to Promote the Development of Intelligent Society
}

\author{
Wang Xiaodi \\ International Information Research Department \\ Beijing Institute of Science and Technology \\ Beijing, China \\ E-mail:wangxd@bjstinfo.com.cn
}

\author{
Meng Jie \\ International Information Research Department \\ Beijing Institute of Science and Technology \\ Beijing, China \\ E-mail:mengj@bjstinfo.com.cn
}

\author{
Zhang Yuan \\ International Information Research Department \\ Beijing Institute of Science and Technology \\ Beijing, China \\ E-mail:zhangy2@bjstinfo.com.cn
}

\begin{abstract}
With rapid development of the Internet, big data, cloud computing, autonomous vehicles, artificial intelligence, 3D printing and other intelligent technologies, the outline of the intelligent society has been more and more clearly presented in front of us. Firstly, this study reviewed current policy of Japan to promote the modernization of super intelligent society, collected Japanese data-driven social development strategy. Secondly, the authors analyzed Japan's technology application cases in 2016 of information technology and artificial intelligence combination application, building energy saving technology development and social intelligence service technology. Finally, according to the research results, the authors proposed form of suggestions for our country to build intelligent social development, strengthen construction technology and optimize intelligent society service quality.
\end{abstract}

Keywords--intelligent society; information technology; big data; future city

\section{INTRODUCTION}

With rapid development of the Internet, big data, cloud computing, autonomous vehicles, artificial intelligence, 3D printing and other intelligent technologies, the outline of the intelligent society has been more and more clearly presented in front of us. "Smart City" is the demand of the era development to promote the intelligent society development, and it cannot be separated from the policy development and technical applications.

\section{INTELligent SOCIETy RELEVANT POLICIES}

Japanese Cabinet Government reviewed and approved the "Fifth Phase of Science and Technology Basic Plan (2016-2020)" in January 2016. This project was present the concept of "Society 5.0", and put forward to create "Super intelligent society" as the development goal. Japan's government expect to develop and create the industrial planning proposed to advance at an equal pace with the industrial internet programming in "National strategic plan for advanced manufacturing" in the United States, and Industrial 4.0 planning of "2020 high technology strategy" in Germany.

To create a "super intelligent society", Japan not only needs to have a proactive and strategic development strategy to respond to diversity and flexibility, but also need to expand competition and coordination in international and open innovation system. So, it will improve infrastructure level in electricity, transportation, energy, communications, and health care. Through science and technology to promote the social system, Japan's government constructed the system framework to maximize the innovation ability of innovation subject.

Japan's implementation of the "Fifth Phase of Science and Technology Basic Plan (2016-2020)" refers to April 2016 to March 2021. This Japanese government comprehensive plan for science and technology in 5 years, and the core concern is to put forward the construction of the world's leading super intelligent society. During project period, there will have scenario analysis of the social economic changes, and propos relevant recommendations for science and technology revitalization.

With the development of information communication technology, network and cyberspace utilization has achieved rapid development. Nowadays, the world science and technology development have significant changes, Japan will establish manufacturing industry as the core, flexible use of information and communication technology, development of powerful networking infrastructure, to build the world's leading "super smart society", and constantly create the new value and new service. In addition, Japan will strengthen the cooperation between the government and Industry, and build a super intelligent social services platform to achieve 
interoperability between different service systems and operation system.

Super intelligent society is a world highly integrated social in network space and the physical, the ultimate goal is to provide the necessary goods and services. It can be very detailed to meet all kinds of society needs. All beyond the age, gender, geography or language and other differences will get high quality service, it can create a happy and comfortable life society ${ }^{[1]}$.

\section{INTELLIGENT TECHNOLOGY SOCIAL APPLICATION}

With the acceleration of the world economic integration process, Japan has continued to carry out intelligent technology innovation, and support the development and application of intelligent technology, and promote the steady development of intelligent building industry and energy saving industry. The Japan's government takes advantage of intelligent technology for industrial creation and social reforming in the future, and strives to create a new value.

\section{A. Combination of information communication and artificial intelligence technology}

Information communication technology and artificial intelligence technology is a pioneer in building process of "intelligent society". In 2016 June 2, Japan NTT Company, Tokyo Wireless Association and Fujitsu has been cooperated and developed a prediction techniques of taxi services demand technology, and it has begun to implement the test. The intelligent information technology aimed to by maximizing the use of information and communication technology, cyberspace and material space could be compromised, so that everyone could extremely enjoy high quality service and convenient life.

This technology was built by three companies and based on big data technology. NTT Company was responsible for data platform system development and operation, Tokyo Wireless Association was responsible for rental vehicles management, Fujitsu was responsible for taxi data collection and processing. The prediction technology used AI (Artificial Intelligence) technology of NTT to establish a taxi demand prediction model which could forecast the number of cars after half an hour. The data that was used include demographic data, Tokyo wireless taxi operation data, time and seasonal cyclical variation trend trends, meteorological data and Peripheral facilities data, etc.. The taxi operation data was collected taxi distribution system and Location information service platform by Fujitsu. The prediction information was obtained through the sound, text and tablet terminals on the map, etc. to provide a wireless taxi driver in Tokyo.

The experimentation would be tested and verified based on the prediction information and the actual taxi operating data, to determine the effectiveness of practical application. According to the data which was obtained in the test, the accuracy of prediction information was verified by technical identification. After the establishment of the mobile demand forecasting technology, the program expanded the scope of service to add

\footnotetext{
${ }^{1}$ Japan Science Portal:

http://scienceportal.jst.go.jp/news/newsflash_review/newsflash/2016/05/2016 0523_01.html
}

taxi company's operating data in Japan. For practical application, it has considered with the taxi company's existing distribution system to achieve low cost import ${ }^{[2]}$.

\section{B. Improving energy efficiency, development of intelligent building energy saving technology}

The development of intelligent building, which was improved the efficiency of energy use, the greatest extent possible to save and reduce energy consumption. It is one of the important standards for the development of intelligent society. In March 23, 2016, Japan New Energy Development Organization (NEDO) announced, NEDO cooperated with New York University to establish "Green energy nanotechnology building" with energy saving technology. This experiment adopted the Japanese technology; the purpose was to lower the building electricity consumption by half.

The United States has been paid amount of attention on energy saving, and also planned to new-built government office in 2030, and reduced the energy consumption of government office building to zero by 2050 . Therefore, it could be predicted that the future development of energy saving technology market has great potential. As early as November 2009, Japan and the United States have reached an agreement to cooperate in green energy field, after the two sides launched a series of joint research activities. In September 16, 2013, Japan New Energy Development Organization (NEDO) signed an agreement with New York University, to advance the practical experiment of energy saving building. For this purpose, the New York University completed the construction of "Green energy nanotechnology building" by 2015 .

Japan's other R \& D institutions and enterprises had also put energy saving technology as the focus development. For example, Japan technology development organization, Japan Shimizu Construction Company had imported a series of technology and equipment in the Green energy nanotechnology building. The introduction of advanced technology in Japan mainly included water intelligent control system, location information system, window-shades lighting system, fuel cell system, and solar photovoltaic power generation system. According to the calculation of these technologies, it could be able to reduce building energy consumption by $54 \%{ }^{[3]}$.

\section{Improving energy efficiency and developing intelligent building energy saving technology}

Social intelligence service is reflected in all aspects of daily life, to increase the industrial productivity and improve in living standards. Japan's Hitachi Limited announced in June 2, 2016, the company will collaborate with the other three companies on smart sensors development which was installed on access cover. A sensor installed in the well lid, to monitoring the cover state uninterruptedly and real-time observation of the underground water in toxic gases, water quality and water yield. The information collected by the

\footnotetext{
${ }^{2}$ Japan YAHOO:

http://headlines.yahoo.co.jp/hl?a=20160531-00000106-zdn_n-sci

${ }^{3}$ Japan New Energy Development Organization (NEDO):

http://www.nedo.go.jp/news/press/AA5_100535.html
} 
sensor will be monitored on the cloud type integrated monitoring platform set up by Hitachi's data center, and provide real-time information to the customers through the monitoring portal. The experimental results are expected to be used in $2016^{[4]}$.

\section{Sustainable supplying data replication technology for information services}

Intelligent society development cannot be separated from the support of big data, but the frequent natural disasters in recent years makes the data maintenance and preservation more and more important. In May 27, 2016, Tohoku University Japan and Hitachi Limited announced that there has successfully developed data replication technology to provide information services and data backup for internet interruption in large-scale disasters.

In March 11, 2011, Great East Japan Earthquake, even though there were still some places in the disaster had network environment, but the connection distance of the wide area network has been destroyed, resulting in data to be inaccessible. And after the earthquake, needs to use personal and family data immediately, how to continue to provide these data has become an urgent issue to be resolved. Hitachi Limited Company has researched and developed the data replication technology to reducing data replication for lower risk server, and to increasing data replication for higher risk server, thereby it obtained a balance between cost and data preservation. In addition, the method of solving the optimization problem is also developed according to the number of replications, which can shorten the calculation time [5]

Japan has been the leading edge in the world in the field of intelligent socialization, to a large extent; the government's strong support cannot be separated.

The implementation of relevant policies and development strategies, the development of intelligent building energy saving technology, the upgrading of social intelligence services, the preservation of large data after disaster, all of above which have created value for the development of intelligent society in Japan.

\section{ENLIGHTENMENTS TO CHINA}

Focus on the development trend of intelligent society, service innovation driven development strategy will also be the focus of future development in China. This article through case analysis and research of Japan, to promote the modernization of super intelligent social development policy, data driven development strategy, information technology, urban intelligent construction, large data storage and maintenance, Summarize the application experience of Japan's policy and technology in related fields, and put forward some suggestions and enlightenments for intelligent society construction in China.

\footnotetext{
${ }^{4}$ NIKKEI: http://techon.nikkeibp.co.jp/atcl/news/16/053102356/

${ }^{5}$ Hitachi Limited:

http://www.hitachi.co.jp/New/cnews/month/2016/05/0527a.html
}

\section{A. Formulating of Intelligent social development strategy}

Japan as one of the best countries leading the development of information technology in the world combined a concerted effort with the government, academia and industry, and vigorously promote the implementation of scientific and technological innovation policy to build Japan become one of the best countries in the world of science and technology innovation. In Japan's "Fifth phase science and technology basic plan", the government will vigorously support policy measures and policy guidance, and in the field of intelligent building enterprises to establish cooperative relations. This initiative plays a key role in the rapid development of intelligent society. Reference to Japan in the construction of intelligent social development strategy, from the perspective of long-term development, and actively respond to social and economic development challenges. China should consolidate science and technology foundation, strengthen information communication technology and artificial intelligence technology development, ensure energy stable supply, improve energy efficiency, build intelligent infrastructure, unified intelligent technology standard system, promote intelligent enterprises industrial alliance, and formulate a comprehensive strategy to maximize the development of intelligent innovation ability.

\section{B. Creating intelligent Internet information service system}

In today's leading life science and technology, intelligent information technology has greatly promoted the development of social and economic development; There has significant impact on social production, life and industrial structure upgrading. First of all, according to cases study of Japanese government in the use of intelligent communication technology, our country not only need to use intelligent information technology for providing high quality and convenient life for people, strengthen the resources and information for sharing between the various regions, but also need to use intelligent communication technology for realizing the resources and information sharing between different regions and different cities, especially in education, health care disaster prevention and transportation. Second, in addition, by drawing on the integration of intelligent communication technology and traditional industries in Japan, we'd like to achieve the further upgrading of traditional industries in China and build a smart social system with Chinese characteristics. Last, we also need to focus on strengthening the development and application of cloud computing and big data processing technology, and real-time monitoring and analysis of all aspects network data (such as water and electricity supply, transportation conditions, weather, medical treatment, etc.) in daily life. So that the development of artificial intelligence technology, drive information science, computer science and other fields to play a stronger role in practical applications.

\section{Developing intelligent building innovative technology industry}

For people living, structures should also adapt to changes in information technology, Japan in the field of intelligent building has an overall comprehensive research, and is also one of the most representative countries to put forward the theory and practice analysis. China should draw lessons from 
the development trend of Japan in architectural skill design, energy system energy saving technology and equipment intelligent automation technology. In the design of building energy efficiency, we should fundamentally reduce energy demand and improve energy saving design innovation, ameliorate China's energy saving design of the most current building assembly lines which lead to the lack of breakthrough innovative design capabilities. Thus, China's government should construct and promote efficient and convenient, energy conservation and environment protection, as well as meet the needs of the public social environment.

\section{REFERENCES}

[1] Tianxiang Tong. The Future Society by Intelligence Technology [J]. Journal of Hangzhou Normal University, 2003, (6):18-22.
[2] Rui $\mathrm{Li}$, Wei $\mathrm{Li}$, Yong Wu. Introduction of intelligent transportation system in Japan and references [J]. China ITS Journal, 2011, (6):123-126.

[3] Ziqiang Hou. People-oriented intelligent building concept in Japan [J]. Computer Knowledge and Technology (Digital Community \& Smart Home), 2006 (3) 103-104.

[4] Xin Jin. Development and application of intelligent information technology [J]. Digital Technology and Application, 2015, (8): 181

[5] Maojing Jin. A brief discussion on the development of intelligent transportation in China [J]. Transportation Science \& Technology, 2013 (2): $140-142$.

[6] Yangdong Ou, Wencai Zhang, Li Lv, Mingdong Ma. High performance building application overview [J]. Electrical Technology of Intelligent Buildings, 2010, 4 (2): 64-67.

[7] Xiwen Wang. Industry 4.0 make smart city to become the carrier of intelligent society [J]. Internet of Things Technologies, 2016,6 (7): 3-4.

[8] Jun $\mathrm{Wu}$. The impact of big data and machine intelligence on the future society [J]. Telecommunications Science, 2015, 31 (2): 1-10 